\title{
Remote Teaching a Foreign Language to Students of Conventional Specialities of the Russian University of Transport during the World Lockdown Because of COVID-19 Spread
}

\author{
Yulia Guro-Frolova ${ }^{1}$, Ekaterina Sedova ${ }^{1}$, Veronika Novik ${ }^{1 *}$ \\ ${ }^{1}$ Volga State University of Water Transport, Nizhny Novgorod, Russia \\ *Email: veronika.novik.75@mail.ru
}

\begin{abstract}
The problem of remote teaching of technical university students of conventional specialities a foreign language is considered. Confident proficiency in a foreign language is one of the conditions for obtaining a promising job in the future. The article compares the productivity of remote learning technologies and the traditional classroom form of teaching a subject in mastering a foreign language by technical university students in the context of a pandemic of novel coronavirus infection. Remote learning shows its productivity, provided that various psychological and pedagogical technologies are combined concerning e-learning, an example of which is given in the article. The success of remote learning is also associated with the generation of psychological comfort during classes, which increases the percentage of students with positive emotional (functional) states.
\end{abstract}

Keywords: Foreign language, Remote learning, Technical university, Productivity, Emotional (functional) states, E-learning, Psychological comfort, Project.

\section{INTRODUCTION}

The modern reality of Russia's entry into the world economic and educational space is such that a severe competitive selection, which employers carry out, presupposes that one of the critical conditions for obtaining a well-paid job is the possession of an applicant for the position of well-formed language competence, which in turn implies a confident command of a foreign language necessary for the effective solution of professionally oriented tasks in the context of dynamically changing requirements for their implementation. Knowledge of a foreign language and free communication in it acts as the main factor in obtaining good work for future specialists in water transport, in particular specialists in the field of navigation on sea routes, which is due to the requirements of the International Convention on Standards of Training, Certification and Watchkeeping for Seafarers, 1978 (hereinafter referred to as the Convention STCW) [1].
The requirements of the STCW Convention are strict since the disregard causes property damage, environmental pollution, and loss of life.

All over the world, special attention is paid to the process of teaching a foreign language to future specialists in water transport (navigators, ship mechanics, etc.) [2-5]. Foreign language teachers are faced with the task of forming a productive, professionally-oriented educational process, increasing the motivation for learning a foreign language, etc. [6-10]. The years 2020 and 2021 have become stressfully significant for the educational systems of all countries of the world, which were forced to implement a remote approach to the organisation of the educational process [11-16].

In Russia, concerning the conventional directions of training specialists in water transport in the implementation of educational programs, a higher educational institution has the right to use e-learning, remote educational technologies; however, a complete 
transition to these forms of work is not allowed, which is understandable, since the quality of training specialists in conventional directions is directly related to possible risks to human life, property, environment, etc.

\section{METHODS}

The purpose of the study was to compare the results of teaching a foreign language at the Volga State University of Water Transport (hence - VSUWT) of students of the speciality 26.05.05 "Navigation" with the use of remote learning technologies and traditional classroom training for a period in the context of a coronavirus pandemic.

The experiment involved 4 students' groups (72 people) 3 courses of the speciality 26.05.05 "Navigation". Classes in two groups were conducted in a remote format (hence - DF groups) by teachers of the age category "65+", who had been transferred to a remote form of work in the context of the spread of novel coronavirus infection. The other two groups were trained standardly during face-to-face instruction (hence - F-F groups).

To implement the educational process in the remote, university teachers have developed remote training courses on the Moodle platform with free access for students of all courses and specialities (areas of training) in each discipline taught. Substantively, the courses duplicate the educational and methodological complexes of disciplines developed at the university and include electronic versions of teaching aids, audio and video materials, video lectures and recommendations for studying the subject, tests, creative assignments, video messages, professionally-oriented projects

As an example of a remote form of work with students of the third course of the speciality 26.05.05, who took part in the experiment, the authors propose a professionally-oriented project, "Mariners' alerting and reporting scheme". The purpose of introducing this project technology, as a set of problem-research methods and teaching techniques, is the productive formation of effective communication skills among students in a foreign language, considering the content component of modern professional competencies with a focus on minimising the negative impact of the "human factor" in conditions of professionally oriented situations at sea, as well as considering the further provision of safe navigation.

During the implementation of the "Mariners' alerting and reporting scheme" project, students are focused on finding the correct optimal solutions to the following proposed problem situations, including considering the communicative component: towing a vessel, collision, mooring, embarking a pilot, passing through channels and narrows, etc. [8].
The authentic Internet resource https://www.gov.uk/maib-reports has been chosen as the primary search base for examples of professional problem situations since the resource contains a large amount of data in the form of reports on incidents at sea over several years. In addition to describing situations, the reports include the results of examinations, professional recommendations, expert conclusions in a foreign language.

\section{RESULTS}

The intermediate certification of students of the DF groups was carried out in a video conference format; the acquired skills of the students of the F-F groups were assessed face-to-face, while the teachers of the other groups were the examiners. The following forms of control were used for the intermediate certification: a lexical and grammatical test, an interview with a teacher on the studied material, translation from English into the native language of a professionally-oriented text (translation of a chart).

During the research, the quantitative ratio of students in the DF and F-F groups who successfully passed the interim certification with the "passed" / "not passed" grade according to the following assessment criteria was determined: "passed" - the student demonstrates confident mastery of the studied material within the semester, the final test is passed. The student reproduced at least $50 \%$ of the phrases from the standard marine navigational vocabulary, confidently translated the chart; "not passed" - the student demonstrates the lack of knowledge of the studied material within the semester, the final test is failed. The student reproduced less than $50 \%$ of the phrases from the standard marine navigational vocabulary, found it challenging to translate a chart.

The results of intermediate certification in the groups DF (36 people) and F-F (36 people) are shown in Figure1. In the course of the analysis of the results of the intermediate certification of students of the 3rd year of the speciality 25.05.05 in the discipline "Foreign language", it can be concluded that in the case with the appropriate approach to the organisation of remote learning and the variation of forms of work within the framework of remote learning, there is no significant difference in the number of students in the DF and F-F groups which got "passed" in the course of intermediate certification.

In the process of experimenting with the students studying remotely, in addition to the important didactic and methodological tasks set by the teachers, special attention was also paid to the psychological and pedagogical aspects, since one of the fundamental goals of the teacher is to maintain and further develop the motivation for learning a foreign language, in particular professional motivation. 


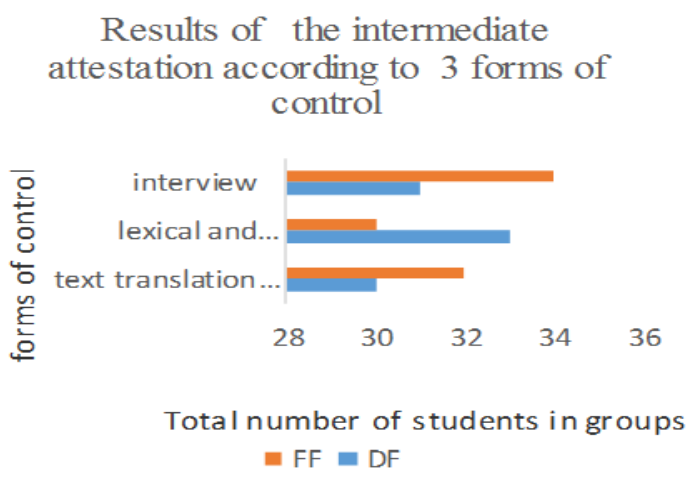

Figure 1 Results of the intermediate attestation of the 3rd year students in the discipline "Foreign language" of face-to-face (F-F) training and training conducted in a remote format (DF).

All the students of the 3-rd year of all specialities studying in VSUVT start learning a professionallyoriented module as part of the program for mastering a foreign language.

Before starting work on the professionally-oriented project" Mariners' alerting and reporting scheme," the students have been asked the following questions: "What are your expectations from training English conducted in a remote format?" "In which format do you prefer to work, in traditional face-to-face or remotely, and why?"

Approximately $60 \%$ of the surveyed students expect the same from remote foreign language learning as from face-to-face training. From their point of view, within the framework of remote learning, it is possible to maintain the current level of a foreign language and acquire new knowledge. In this regard, students noted that mastering knowledge of a foreign language and improving language proficiency largely depends on the students themselves, not on the format of training. In both remote and full-time forms, students have the opportunity to use Internet resources, where they are allowed to find a considerable amount of relevant information for classes, including professionally oriented. From the point of view of the above $60 \%$ of the students surveyed, close contact with a teacher is also possible in the implementation of remote learning. A student can also contact a teacher for help by making a phone call or sending a message using modern instant messengers (Viber, WhatsApp, etc.); communication by e-mail is also widespread. Students among the respondents (60\%) practically do not see the difference between face-to-face training and remote learning. In this regard, one can even conclude that remote learning for this category of surveyed students is preferable. The students also noted that being trained in a remote format allows students to devote more time to a foreign language since they have free time, which is not enough face-to-face training. At home, students feel psychological and physical comfort; since more time is spent on rest and sleep, there is no need to spend time getting to the university.
$30 \%$ of the surveyed students did not speak out against remote learning, noted its convenience in comparison with full-time education; however, their expectations from learning a foreign language in a remote format are not high. Among the disadvantages of training conducted in a remote form, students noted the inability to meet with the teacher personally. Students believe that it is not always convenient to bother the teacher with phone calls, messages via e-mail, especially in the evening. A student has to do a significant part of the work independently; reference books, video lessons found on the Internet are not always informative, resulting in knowledge gaps arising and the teacher's participation and work in a group are required. Students belonging to this category of respondents are depressed because there is no personal communication with classmates; thus, teamwork skills, which are fundamental in project activities, are lost.

Among the students surveyed, $5 \%$ turned out to be opponents of training conducted in a remote format. At the same time, the students are convinced that it is impossible to gain knowledge while studying remotely, or the quality of knowledge will be low since in the process of answering the tasks received online; there is a temptation to write off, find the correct answer in the available notes, slides and notes to the project, resort to tricks of a different kind, which the teacher may not be aware of. Expectations from training conducted in a remote format for students in this category turned out to be low due to the lack of technical ability to go online. Some students live in settlements with a weak or unstable Internet connection; some students explain the impossibility of going to the online conference by the fact that there are also members of the family who live with them, their brothers or sisters who are schoolchildren or students, or parents working online, who need a computer at the same time as they need, and the family has the only one computer.

As a result of the analysis of the answers to the questions, the teachers considered it expedient to study students' emotional (functional) states. In this regard, the respondents were asked the following question: "What feelings, emotions do the forthcoming work on a project in a remote format evoke in you?"

$5 \%$ of respondents noted such emotions as satisfaction, delight, joy, desire to gain new knowledge, emotional uplift. Such emotional states belong to the first group, classified as non-equilibrium states of a positive modality. Students belonging to this category show a sincere interest in the subject, trying to study it deeply and comprehensively, guided by cognitive rather than pragmatic motives to a greater extent. In the future, most of the students in this group plan to engage in scientific activities, build a scientific career. As practice shows, such states are quite rare among students. 
$70 \%$ of the surveyed students, the overwhelming majority, experience such emotions as attention, composure, concentration, satisfaction, calmness, curiosity, curiosity. These emotions belong to the second group of emotions - relatively balanced mental states of a positive modality. These mental states are calmer compared to the emotional (functional) states belonging to the first group. Such conditions are characteristic of highly motivated students who enthusiastically study a subject, in our case, a foreign language. A certain part of the students belonging to this group, presumably future postgraduate studies, defend a $\mathrm{PhD}$ thesis and have conversations with foreign colleagues at sea. It is important to note that the percentage of students who reported emotions related to the second group of emotional (functional) states is relatively high. As a rule, students studying at the Navigation Department have a good command of the foreign language and consciously choose the profession of a maritime engineer.

$10 \%$ of respondents noted such emotions as tension, anxiety, stress, excitement, fear, tension. A small part of this percentage of students stated the presence of such emotions as dislike, indignation. We positively note that the students included in this category of respondents did not note the presence of such emotions as aggression, anger, anger, rabies. Such emotions and those mentioned above belong to the third group of emotional (functional) states, the so-called non-equilibrium negative states. Such conditions, particularly aggression, rabies, anger, anger, can be characteristic of unmotivated students who perceive a certain kind of activity, in our case educational, as heavy-duty. Perhaps these are the students who study a specific profession against their will, and the choice for them was made by third parties (parents, other relatives, acquaintances).

As for the sampling during the experiment, it is quite natural that the students experienced a feeling of excitement, anxiety since the educational process in a remote form turned out to be a new type of educational activity for them. Students and other individuals experience fear of the new, previously unknown.

$10 \%$ of students noted the emotions of confusion, dissatisfaction, disappointment, annoyance, which constitute the fourth group of emotional (functional) states - balanced negative states. These emotions are associated with a new activity, and as mentioned above, some students expressed a negative attitude to training conducted in a remote in general.

$5 \%$ of students in the experimental sample stated the presence of a feeling of helplessness, and as a result, dissatisfaction, disappointment. This percentage of students included students who noted such emotions as laziness, apathy, drowsiness, boredom, melancholy. Unfortunately, we can state that there is a certain number of lazy, apathetic students who do not feel like learning and acquiring professional skills among the students. The emotions mentioned above belong to the fifth group of emotional (functional) states - negative states of decreased mental activity.

The emotional (functional) states of the experimental sample of students whose training has been conducted in the remote format before the implementation of a professional project, active teaching methods and intermediate certification are shown in Figure 2.

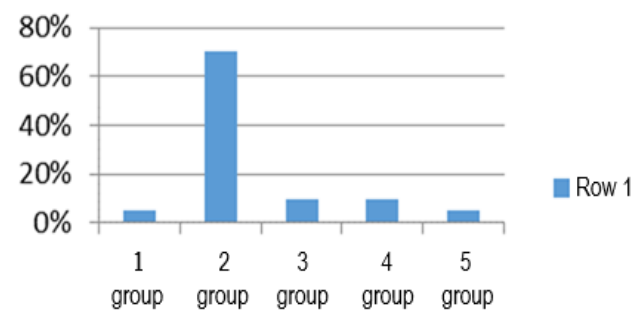

Figure 2 The severity of the functional (emotional) states of students who studied remotely before the introduction of a professional project, active methods and intermediate certification, $\%$.

The obtained data are statistically reliable $(\rho \leq 0.01)$

\section{DISCUSSION}

Based on the obtained results, teachers who have conducted training in a remote format concluded that there is a need for an optimally organised process of training a foreign language in a technical university in a remote format. It should be organised in such a way as to provide students with psychological comfort during classes and preparation for project activities, as well as to increase the percentage of students with emotional (functional) states of a positive orientation and reduce the percentage of students with emotional (functional) conditions of a negative nature, in particular, to help reduce emotional stress, anxiety, anxiety, fear, resulting in a feeling of self-doubt, frustration, dissatisfaction.

When organising teaching a foreign language in a remote format, to maintain the motivation of learning a foreign language, the motivational model of J. Keller ARCS (Attention, Relevance, Confidence, Satisfaction) was considered [15].

Attention is the basis for the successful maintenance and development of students' motivation, particularly in remote learning. The required study material should be organised in such a way as to interest the student. While learning a foreign language at a technical university, the students often read professional texts, perform pre-text and post-text exercises during the classes. The monotonous reading of the text and the following question-and-answer activities cause students' boredom, drowsiness, and sad emotional states. Unfortunately, teachers cannot ignore this type of work because students must master a certain lexical minimum. However, there 
is always the opportunity to diversify the kinds of work in the classroom. The Department of foreign languages teachers of VSUWT has developed complex, interesting, colourful, informative educational presentations containing up-to-date and authentic material. Presentations of this kind are demonstrated within the framework of videoconferences on the Zoom platform in the screen sharing mode. Such illustrative material contributes to the development of the mental process of attention, which is ultimately associated with better assimilation of the necessary information.

An equally important component of the above motivational model is Relevance. As mentioned above, teaching materials should be informative and interesting in connection with the development of students' attention. However, beyond that, to develop and maintain motivation, students need to be convinced that the materials are meaningful. The Department of foreign languages teachers, working at Navigation Department, offer students a vast amount of modern authentic information, particularly sailing directions, which students carefully study and translate; the information obtained is later used in practice. In the arsenal of teachers, there are also many video clips dedicated to various problem situations that navigators may encounter at sea, and students carefully look through, condemn with teachers and classmates, and receive written assignments after watching a certain fragment. Along with the practical significance, various types of speech activity (listening, speaking, reading, writing) develop communicative competence through actual authentic materials.

However, when it comes to watching videos, teachers often face some difficulties working remotely. Video fragments take up a large amount of memory, so it is difficult to play them back in the screen sharing mode during a conference in zoom. One of the ways out of this situation is to share with students a valid link to a particular video so that students can watch it.

Confidence is an equally important component of the motivational model. To instil confidence in the student, encouraging him to believe in himself is one of the main tasks of the teacher. In this case, the independent work of students, in particular, work on a project, where he has the opportunity to choose information independently, using various sources, analysing them, is an effective means. Work on the project is carried out under the guidance of a teacher, in the form of a constructive dialogue, the teacher guides and corrects the student's activities; however, the student performs the main work independently: collects and analyses information, creates a presentation, selecting slide designs and special effects. In autonomous work, the student feels his significance and develops self-confidence.

At the top of J. Keller's motivational model is satisfaction. As a result of the methodologically and psychologically correct organisation of the remote learning process, it is possible to generate moral satisfaction from work done.

After the intermediate certification, repeated analysis of the functional (emotional) states of students who have studied remotely was carried out. The students were asked, "How has your attitude to training a foreign language in a remote format been changed? What feelings, emotions concerning remote learning do you have at the moment?"

The analysis of the received answers to the question showed that most students, working in a psychologically comfortable, calm atmosphere, changed their attitude to remote learning, and to a greater extent noted such emotions as satisfaction, calmness, emotional uplift.

The emotional (functional) states of a sample of students studying in a remote learning format after the introduction of a professional project into the educational process and intermediate certification are shown in Figure 3:

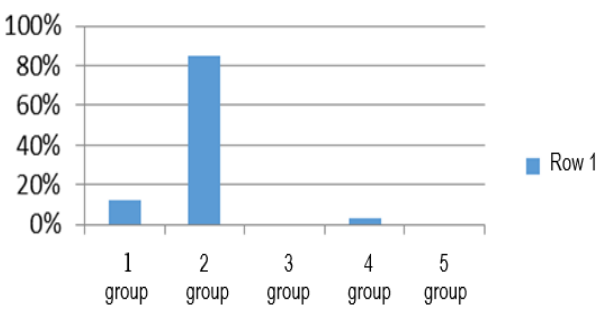

Figure 3 The severity of the functional (emotional) states of students who studied remotely after the introduction of a professional project into the educational process and intermediate certification, $\%$.

The positive qualitative dynamics of students' emotional (functional) states at the end of the project work and after the intermediate certification is shown. The percentage of emotional (functional) states belonging to the first group increased - non-equilibrium conditions of a positive modality (from 5 to $12 \%$ ), as well as the percentage of emotional (functional) states belonging to the second group - equilibrium states of a positive modality (from 70 to $85 \%$ ). The fact that the percentage of equilibrium negative states has significantly decreased (from 10 to 3\%) is also encouraging. There were no students with nonequilibrium negative conditions (third group) and decreased mental activity (fifth group).

The obtained data are statistically reliable $(\rho 0.01)$.

\section{CONCLUSION}

The quality of training specialists of conventional specialities of water transport is of paramount importance since it is associated with possible risks for human life, the environment, and property in the future. Partial 
transition to remote e-learning for students of conventional specialities (navigators, ship mechanics and electromechanics) in 2020 due to the pandemic and the spread of the new coronavirus infection around the world showed that with the help of an optimally organised educational process for mastering the discipline with a variety of different forms of remote work, the results of teaching a foreign language using remote learning technologies and traditional face-to-face training for the period in the context of the coronavirus infection pandemic do not differ significantly. By an optimally organised educational process, the authors mean the process in which they use: a) a pre-developed electronic course that duplicates the main program for the discipline, containing electronic teaching aids, audio and video materials for mastering the subject, recommendations, grammar guides, test tasks to control knowledge; b) parallel to the implementation of the e-course, communication in the format "teacher-studentgroup of students" through video conferences with the possibility of live online communication in a foreign language.

\section{AUTHOR CONTRIBUTION}

Y.G. conceived of the presented idea. E.S. and developed the theory, designed the model and performed the computations. E.S. verified the analytical methods. All authors discussed the results and contributed to the final manuscript. Y.G. and E.S. carried out the experiment. E.S and V.N. developed the theoretical formalism, performed the analytic calculations and the numerical simulations. Y.G. supervised the project. All the authors provided critical feedback and helped shape the research, analysis and manuscript.

\section{ACKNOWLEDGMENTS}

The authors would like to express gratitude to the Dean of Navigation Department of the Volga State University of Water Transport, Mr Churin M.Y, for his valuable and constructive suggestions during the planning and development of our article. We would also like to thank the Head of the Navigation Department of the Volga State University of Water Transport, Mr Khvostov R.S., for his help and support.

\section{REFERENCES}

[1] International Convention on Standards of Training, Certification and Watchkeeping for Seafarers, 1978 (London, July 7, 1978) (with amendments and additions) [Electronic resource]. URL: http: //base.garant.ru/2540787/\#friends (date accessed: 01/22/2021).

[2] Raju Ahmmed, Begum Shahnaz Sinha, Dr Rubina Khan, Dewan Mazharul Islam, A needs analysis of maritime English language skills for Bangladeshi seafarers to work on-board ships, Marine Policy 119 (2020) $104041 . \quad$ DOI: https://doi.org/10.1016/j.marpol.2020.104041 Retrieved from: https://www.sciencedirect.com/science/article/pii/S 0308597X20301044

[3] Lidong Fan, Jiangang Fei, Ulf Schriever, Si Fan, A critical examination of the seafaring English education and training in China, Marine Policy 86 (2017) 56-63. DOI: https://doi.org/10.1016/j.marpol.2017.09.013

Retrieved from: https://www.sciencedirect.com/science/article/pii/S $\underline{0308597 X 17303937}$

[4] Peter John, Benjamin Brooks, Ulf Schriever, Profiling maritime communication by non-native speakers: A quantitative comparison between the baseline and standard marine communication phraseology, English for Specific Purposes 47 (2017) $1-14$.

DOI: https://doi.org/10.1016/j.esp.2017.03.002

Retrieved from: https://www.sciencedirect.com/science/article/pii/S $\underline{0889490617301047}$

[5] Goudarz Alibakhshi, Reza Javaheri, Akram Labbafi, Academic and real-life task-based language needs of marine engineering students: interface between students 'and subject teachers' perspectives, Heliyon 7(2) (2021) e05534. DOI https://doi.org/10.1016/j.heliyon.2020.e05534

Retrieved from: https://www.sciencedirect.com/science/article/pii/S 240584402032377X

[6] Lidong Fan, Jiangang Fei, Ulf Schriever, Si Fan, A critical examination of the seafaring English education and training in China, Marine Policy 86, (2017) 56-63. DOI https://doi.org/10.1016/j.marpol.2017.09.013.

Retrieved from: https://www.sciencedirect.com/science/article/pii/S $\underline{0308597 X 17303937}$

[7] Peter John, Benjamin Brooks, Ulf Schriever, Speech acts in professional maritime discourse: A pragmatic risk analysis of bridge team communication directives and commissive in fullmission simulation, Journal of Pragmatics 140 (2019) 12-21. DOI: https://doi.org/10.1016/j.pragma.2018.11.013

Retrieved from: https://www.sciencedirect.com/science/article/pii/S $\underline{037821661830033 \mathrm{X}}$

[8] Yu.R. Guro-Frolova, Methodological aspects of teaching a foreign language in a technical university 
in a remote format/Improving teaching methods at a technical university: a collection of scientific papers based on the materials of the All-Russian Scientific and Methodological Conference, Voronezh, May 19, 2021 / ed. O.R. Dornyak; Ministry of Science and Higher Education of the Russian Federation, VGLTU, Voronezh, 2021, 199 p. DOI: https://doi.org/10.34220/ITMTU2021_22$\underline{26}$

[9] E.A. Sedova, The structure of the methodological manual on a foreign language for undergraduates in a non-linguistic university (on the example of the speciality 08.04.01. Construction) / Improving teaching methods at a technical university: a collection of scientific papers based on the materials of the All-Russian Scientific and Methodological Conference, Voronezh, May 19, 2021 / ed. O.R. Dornyak; Ministry of Science and Higher Education of the Russian Federation, VGLTU, Voronezh, 2021. DOI: https://doi.org/10/34220/ITMTU2021_176-179

[10] V.Yu. Novik, Design and research activities in foreign language lessons as an effective means of professional orientation of a student. A collection based on the proceedings of the 21 st International Congress "Great Rivers", Issue 8, 2019.

[11] Asmat Ara Shaikh, Anuj Kumar, Kruti Jani, Saloni Mitra, Diego A. García-Tadeo, Agilandeswari Devarajan, The Role of Machine Learning and Artificial Intelligence for making a Digital Classroom and its sustainable Impact on Education during Covid-19, Materials Today: Proceedings, 2021, DOI: https://doi.org/10.1016/j.matpr. 2021.09.368 Retrieved from: https://www.sciencedirect.com/science/article/pii/S 2214785321062507

[12] Angel Mukuka, Overson Shumba, Henry M. Mulenga, Students' experiences with remote learning during the COVID-19 school closure: implications for mathematics education, Heliyon, 7(7) (2021) e07523. DOI: https://doi.org/10.1016/j.heliyon.2021.e07523

Retrieved from: https://www.sciencedirect.com/science/article/pii/S 2405844021016261

[13] Sin-Hyang Kim, Sihyun Park, Influence of learning flow and remote e-learning satisfaction on learning outcomes and the moderated mediation effect of social-evaluative anxiety in nursing college students during the COVID-19 pandemic: A crosssectional study, Nurse Education in Practice 56 (2021) $103197 . \quad$ DOI: https://doi.org/10.1016/j.nepr.2021.103197
Retrieved from: https://www.sciencedirect.com/science/article/pii/S 147159532100233X

[14] J.M. Keller, An integrative theory of motivation, volition, and performance. Technology, Instruction, Cognition, and Learning, No. 6(2), 2008.

[15] Tilahun Adamu Mengistie, Higher Education Students' Learning in COVID-19 Pandemic Period: The Ethiopian Context, Research in Globalization 3 (2021) $100059 . \quad$ DOI: https://doi.org/10.1016/j.resglo.2021.100059 Retrieved from: https://www.sciencedirect.com/science/article/pii/S 2590051X21000241

[16] Frank van Cappelle, Vidur Chopra, Jim Ackers, Perman Gochyyev, An analysis of the reach and effectiveness of remote learning in India during school closures due to COVID-19, International Journal of Educational Development 85 (2021) 102439. DOI: $\quad$ https://doi.org/10.1016/j. ijedudev.2021.102439 Retrieved from: https://www.sciencedirect.com/science/article/pii/S $\underline{07}$ 